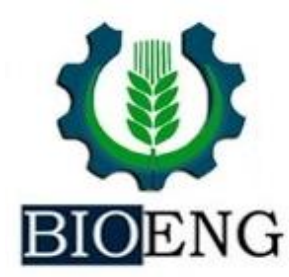

\title{
ESTUDO DA TOXICIDADE DO GLIFOSATO NA GERMINAÇÃO DE COUVE E RABANETE
}

\author{
F. B. Villa*, J. O. F. Monteiro, G. B. Godoy, D. S. S. Souza, J. L.
}

Ramos, A. B. Dias, A. L. R. Portela, G. A. Cristiano, I. R. G. Godoi, L. Gabriel, M. C. Volpe, V. D. D. Neves, R. Sebastiani, R. T. Pelegrini

UFSCar - Universidade Federal de São Carlos, Centro de Ciências Agrárias, Campus Araras, SP, Brasil

Article history: Received 01 October 2019; Received in revised form 04 November 2019; Accepted 06 November 2019; Available online 05 December 2019.

\section{RESUMO}

$\mathrm{O}$ presente trabalho teve como objetivo avaliar os efeitos tóxicos do glifosato (N(fosfonometil)-glicina), um herbicida muito utilizado na agricultura brasileira, como agente estressor, através de uma metodologia de avaliação de toxicidade crônica e aguda nas sementes de couve (Brassica oleracea L.) e rabanete (Raphanus sativus L.). A metodologia escolhida possibilitou a análise dos parâmetros CENO (Concentração de Efeito Não Observável), $\mathrm{CEO}$ (Concentração de Efeito Observável) e $\mathrm{CE}_{50}$ (Concentração Efetiva) para cada uma das espécies. Tratando-se do rabanete, foi observado que o CENO aparecia em 1 $\mathrm{mg} . \mathrm{L}^{-1}$ de agente estressor, o $\mathrm{CEO}$ em $2 \mathrm{mg} . \mathrm{L}^{-1}$ e o $\mathrm{CE}_{50} \mathrm{em}$ aproximadamente $7 \mathrm{mg} . \mathrm{L}^{-1}$. Para a couve, observou-se o aparecimento do CENO em $16 \mathrm{mg} . \mathrm{L}^{-1}$, o CEO em $18 \mathrm{mg} . \mathrm{L}^{-1}$ e o $\mathrm{CE}_{50}$ entre 14 e $15 \mathrm{mg} . \mathrm{L}^{-1}$. Foi possível ter, através do estudo, um alto controle do valor de $\mathrm{pH}(7,0$ para o rabanete e 7,5 para a couve), elevada sensibilidade e baixo custo se comparado a outros testes de toxicidade.

Palavras-chave: glifosato, $\mathrm{CENO}, \mathrm{CEO}, \mathrm{CE}_{50}$

\section{GLYPHOSATE TOXICITY STUDY IN CABBAGE AND RADISH GERMINATION}

\begin{abstract}
This work aimed to evaluate the toxic effects of glyphosate (N- (phosphonomethyl) -glycine), a herbicide widely used in Brazilian agriculture, as a stressor, through a methodology of evaluation of chronic and acute toxicity in cabbage (Brassica oleracea L.) and radish (Raphanus sativus L.) seeds. The chosen methodology allowed the analysis of the parameters NOEC (Not Observable Effect Concentration), LOEC (Lowest Observable Effect Concentration) and $\mathrm{EC}_{50}$ (Effective Concentration) for each species. For radish, it was observed that NOEC appeared in $1 \mathrm{mg} \mathrm{L}^{-1}$ stressor, LOEC at $2 \mathrm{mg} \mathrm{L}^{-1}$ and $\mathrm{EC}_{50}$ at approximately $7 \mathrm{mg} \mathrm{L}^{-1}$. For cabbage, NOEC appeared at $16 \mathrm{mg} \mathrm{L}^{-1}$, LOEC at $18 \mathrm{mg} \mathrm{L}^{-1}$ and

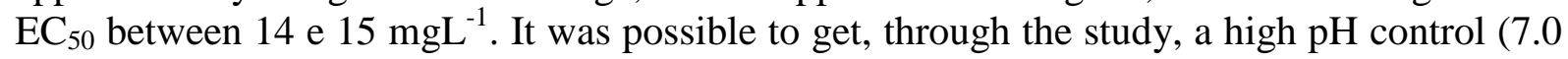
for radish and 7.5 for cabbage), high sensitivity and low cost compared to other toxicity tests.
\end{abstract}

Keywords: glyphosate, NOEC, LOEC, $\mathrm{EC}_{50}$

*felipebernegossi@gmail.com 


\section{INTRODUÇÃO}

Entre os contaminantes decorrentes das atividades antropogênicas, os agroquímicos são das classes mais perigosas, justamente pelo fato de terem sido criados para eliminar alguma forma de vida e, devido a isto, atingirem também de modo letal espécies não-alvo. Logo, se não utilizado corretamente, pode ser prejudicial até mesmo onde não é aplicado (GRISOLIA, 2005).

O glifosato é um herbicida de difícil monitoramento em amostras ambientais, por possuir propriedades de amplo espectro, controlando diversas espécies de plantas daninhas, ser sistêmico e mostrarse menos tóxico a animais do que para plantas. Tornou-se o mais utilizado no mundo, aumentando, assim, a necessidade de implementação de programas de monitoramento (AMARANTE JR et al., 2002).

Uma das mais importantes características deste herbicida é a sua rápida translocação das folhas da planta tratada para as raízes, rizomas e meristemas apicais. Esta propriedade sistêmica resulta na destruição total de plantas, não tendo ação somente sobre elas, mas também sobre as sementes no solo, revelando o grau de toxidade que o herbicida possui (YAMADA \& CAMARGO, 2007).

Este agente estressor age na inibição enzimática das plantas, a partir da enzima 5-enolpiruvilchiquimato-3-fosfato sintase (EPSPs), que é responsável pela síntese dos aminoácidos aromáticos essenciais (fenilalanina, tirosina e triptofano), os quais são precursores de outros produtos, como a lignina, alcaloides, flavonoides, ácidos benzoicos e vitamina K (TONI et al., 2006; GRUYS, 1999). Estes produtos são importantes para a vida das plantas, uma vez que estão associados à proteção contra herbívoros, justamente o efeito procurado ao usar-se o glifosato.

Quando a molécula do glifosato chega ao solo, pode sofrer os processos de degradação e/ou adsorção. Quando adsorvido, seus resíduos degradados podem sofrer um desses processos: absorção das moléculas pelas plantas ou a lixiviação das moléculas para camadas subsuperficiais do solo, podendo assim atingir o lençol freático (TONI et al., 2006).

O glifosato no solo apresenta alta capacidade de adsorção, sendo mais comuns as trocas de ligantes com os óxidos de ferro e alumínio, e as pontes de hidrogênio formadas entre o glifosato e as substâncias húmicas presentes no solo (DA CRUZ, 2002).

A aplicação deste agrotóxico pode resultar na presença de resíduos na colheita das plantas e nos animais, que podem ser usados na alimentação humana. A presença de poluentes nos sistemas aquáticos pode ser letal para grandes populações de organismos bentônicos, causando uma grande desorganização aos níveis ecológicos, sendo resultado da ação do glifosato nas estruturas do tecido, no crescimento e desenvolvimento físico, na reprodução, entre outros. No organismo dos peixes, as brânquias formam o sistema respiratório desse animal e são organizadas de forma a realizar as trocas gasosas, momento em que há a exposição de um sistema de capilares à água, ou seja, tornando o tecido vulnerável em relação ao meio ambiente, pois partículas do herbicida podem causar efeitos danosos às brânquias, consequentemente chegando ao homem através da cadeia alimentar (SILVA, 2004).

Diante de poucos estudos toxicológicos sobre o efeito do glifosato na germinação de sementes e no crescimento de plântulas de couve e rabanete, este trabalho teve como objetivo quantificar o efeito do glifosato em ensaios de toxicidade aguda $\left(\mathrm{CE}_{50}\right)$ e crônica (CENO/CEO), avaliando o efeito tóxico na germinação e desenvolvimento das sementes, visando os impactos ambientais provocados pelo herbicida. 


\section{MATERIAL E MÉTODO}

O desenvolvimento desta metodologia seguiu os procedimentos descritos por Pelegrini et al. (2014) para o preparo dos tampões, solução de nutrientes e produção do meio de cultivo modificado para a adição do glifosato. Para avaliar o desenvolvimento das plântulas foi empregado a Regra para Uso de Sementes em Ensaios Toxicológicos (RUSET), descrita por Souza et al. (2019). A escolha destas técnicas deu-se pelo uso de sementes como organismos testes, produção do meio de cultura de forma simplificada, elevada sensibilidade e baixo custo. Os estudos foram realizados em triplicata para melhor verificação estatística.

\section{Preparo da solução de nutrientes}

É denominada solução de nutrientes a que contém concentrações otimizadas de macro e micronutrientes necessários para o desenvolvimento de plântulas. A solução de nutrientes pode ser preparada em diversos valores de $\mathrm{pH}$ de acordo com a variação das soluções tampão as quais são empregadas no preparo. Os tampões são preparados nos valores de $\mathrm{pH}$ desejados aos ensaios e empregam, em si, os nutrientes que farão parte do meio de cultivo. As concentrações e os nutrientes utilizados estão apresentados na Tabela 1 .

As soluções foram preparadas separadamente e acrescidas com volumes conforme indicados na Tabela 2, sendo completado o volume da solução para 1000 $\mathrm{mL}$ com água destilada. A escolha do $\mathrm{pH}$ foi feita por meio de ensaios prévios utilizando couve e rabanete sem agente estressor em pH 4,0; 5,0; 6,0; 6,5; 7,0; 7,5; 8,$0 ; 9,0$, sendo utilizado o $\mathrm{pH}$ que mostrou maior desenvolvimento.

Na Tabela 2, encontram-se também os volumes dos tampões em valores de $\mathrm{pH}$ 7,0 para o preparo de solução de nutrientes do rabanete e na Tabela 3, os volumes dos tampões em valores de $\mathrm{pH}$ 7,5 para o preparo de solução de nutrientes da couve.

Tabela 1. Concentrações de macro e micronutrientes nas soluções de nutrientes

\begin{tabular}{|c|c|c|c|c|c|c|c|}
\hline Nutrientes & $\mathbf{K}$ & $\mathbf{P}$ & $\mathbf{N}$ & $\mathbf{C a}$ & $\mathbf{M g}$ & $\mathbf{B}$ & Mo \\
\hline mg. $\mathbf{L}^{-\mathbf{1}}$ & 61,00 & 41,00 & 35,00 & 20,00 & 38,00 & 0,30 & 0,06 \\
\hline
\end{tabular}

Tabela 2. Concentrações e volumes das soluções estoque para elaboração da solução de nutrientes. Solução tampão no valor de pH 7,0.

\begin{tabular}{|c|c|c|c|c|c|c|c|}
\hline 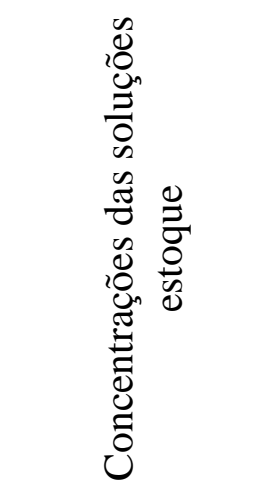 & 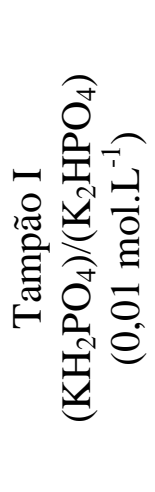 & 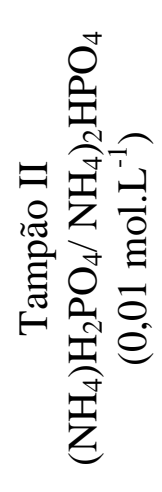 & 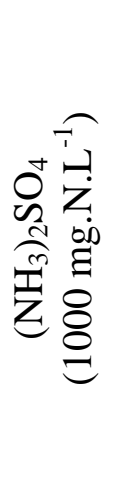 & 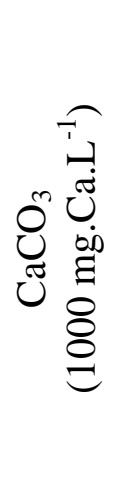 & 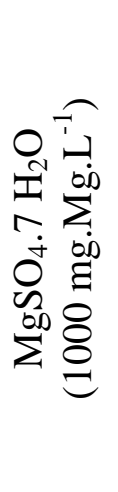 & 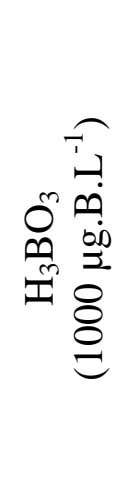 & 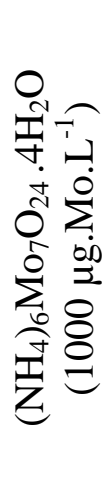 \\
\hline $\begin{array}{c}\text { Volumes } \\
\text { utilizados (mL) }\end{array}$ & 100,6 & 31,9 & 28,7 & 20,0 & 38,0 & 300,0 & 60,0 \\
\hline
\end{tabular}


Tabela 3. Concentrações e volumes das soluções estoque para elaboração da solução de nutrientes. Solução tampão no valor de pH 7,5.

\begin{tabular}{|c|c|c|c|c|c|c|c|}
\hline 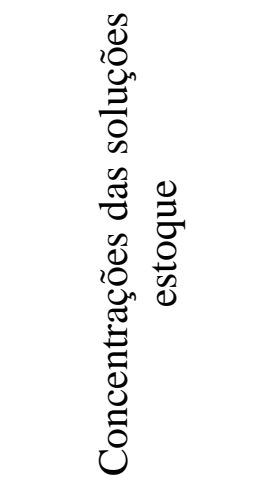 & 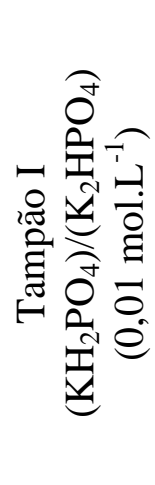 & 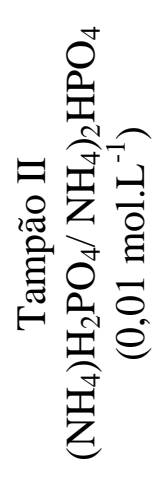 & 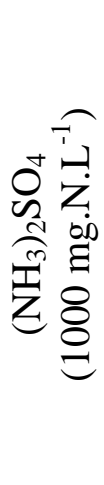 & 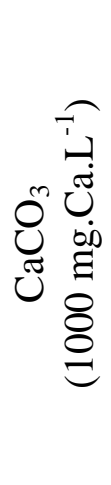 & 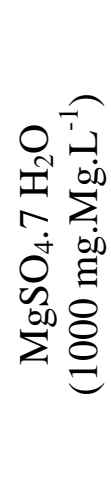 & 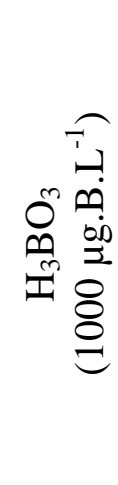 & 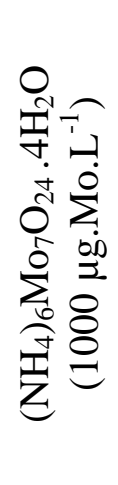 \\
\hline $\begin{array}{c}\text { Volumes } \\
\text { utilizados }(\mathrm{mL})\end{array}$ & 86,7 & 45,8 & 23,8 & 20,0 & 38,0 & 300,0 & 60,0 \\
\hline
\end{tabular}

\section{Preparo do meio de cultivo}

Para preparar o meio de cultivo, empregou-se $0,8 \mathrm{~g}$ de ágar dissolvido em $100 \mathrm{~mL}$ de solução de nutrientes. Utilizouse um béquer de $250 \mathrm{~mL}$ para aquecimento da mistura em chama de bico de Bunsen, com o auxílio de um tripé com tela de amianto, até a fervura para total dissolução do ágar.

Após a fervura, aguardou-se a temperatura atingir aproximadamente 45 ${ }^{\circ} \mathrm{C}$ e adicionou-se $1,0 \mathrm{~mL}$ de solução de agente estressor (em concentrações de [0 mg.L $\left.\mathrm{L}^{-1}\right]$ a $\left.\left[20 \mathrm{mg} . \mathrm{L}^{-1}\right]\right)$ e duas gotas de água sanitária (a fim de minimizar espécies patógenas e desenvolvimento de fungos). Com auxílio de uma bagueta de vidro, homogeneizou-se a mistura ainda líquida.

As soluções de agente estressor foram preparadas por meio da solução estoque de [100 mg. $\left.\mathrm{L}^{-1}\right]$ de glifosato. Para comparação do desenvolvimento das plântulas, foi empregado o uso de amostras sem adição de agente estressor (controle).

Para o preparo dos ensaios, dividiuse o conteúdo do meio de cultivo ainda líquido (temperatura aproximada de $40{ }^{\circ} \mathrm{C}$ ), em volumes iguais (em torno de $30 \mathrm{~mL}$ ) em três recipientes de polipropileno transparente $(250 \mathrm{~mL})$. Após o enrijecimento do meio de cultivo, foram acondicionadas $\quad 30 \quad$ sementes, homogeneamente, em cada frasco.

Os recipientes foram, por fim, fechados e submetidos à luz natural (em ambiente fresco, sem exposição direta do sol) até serem avaliadas ao final do quarto dia de exposição (análise de toxicidade aguda) e do sétimo dia de exposição (análise de toxicidade crônica) utilizando a RUSET para avaliação.

Os estudos de toxicidade avaliam os efeitos adversos provocados por poluentes químicos a organismos vivos (organismoteste). Tais efeitos podem ser quantificados através de manifestações que são provocados as espécies testes.

\section{Toxicidade aguda}

A toxicidade aguda estuda os efeitos letais para os organismos-teste e avalia a concentração capaz de apresentar efeitos para $50 \%$ dos organismos $\left(\mathrm{CE}_{50}\right)$ em até 96 horas. No caso deste estudo foi avaliado o desenvolvimento da planta que apresentou alguma manifestação de toxicidade.

\section{Toxicidade crônica}

Os testes de toxicidade crônica têm por objetivo a avaliação do efeito subletal no organismo-teste através do CENO (Concentração de Efeito Não Observável) e CEO (Concentração de Efeito Observável), no que diz respeito à maior e menor concentração do agente tóxico para que de fato haja toxicidade. Para a toxicidade crônica verificada nesse trabalho empregou um tempo de 168 horas (7 dias) de exposição aos efeitos adversos provocados pelo glifosato. 


\section{RESULTADOS E DISCUSSÃO}

Nos estudos de toxicidade aguda com a couve no valor de $\mathrm{pH}$ 7,5 observouse o aparecimento de efeito tóxico (CENO) a partir de $18,0 \mathrm{mg} . \mathrm{L}^{-1}$ de concentração do glifosato. Sendo que o $\mathrm{CE}_{50}$ apareceu nas concentrações entre 14,0 e $15,0 \mathrm{mg} . \mathrm{L}^{-1}$ (Figura 1 e 3). Isso significa que o glifosato apresenta uma alta toxicidade para esta espécie, dado que as concentrações do agente estressor são baixas se comparados com estudos utilizando a ureia frente à mesma espécie (SOUZA et al, 2019).

No caso do estudo empregando a semente de rabanete, a sensibilidade apresentou-se muito maior sendo que os efeitos tóxicos começaram a ser observado a partir de 2,0 mg. $\mathrm{L}^{-1}$ indicando que a percepção da planta para o efeito tóxico do glifosato pode estar em concentrações em torno de $\mu \mathrm{g} . \mathrm{L}^{-1}$. A concentração subletal observada para o $\mathrm{CE}_{50}$ indica valor de aproximadamente 7,0 mg. $\mathrm{L}^{-1}$ (Figura $2 \mathrm{e}$ 4), o que mostra a gravidade do efeito tóxico do glifosato e também a sensibilidade da espécie para a percepção do agente tóxico. No caso do rabanete, os efeitos letais foram muito mais intensos, dado que as concentrações de glifosato foram extremamente baixas, se comparado com a couve.

No caso da couve, para toxicidade crônica, verificou-se que não houve efeito toxico até a concentração de 16,0 mg.. $\mathrm{L}^{-1}$, indicando que nesta concentração encontra-se o CENO. A partir de 18,0 mg. $\mathrm{L}^{-1}$ apresentou-se toxicidade progressiva no seu crescimento indicando que este seria o CEO (Figura 3).

No rabanete, observou-se efeito tóxico a partir de 2,0 mg. $\mathrm{L}^{-1}$ podia ser verificado o CEO (Figura 4). A partir desta concentração os efeitos adversos provocados pelo glifosato ao rabanete foram progressivamente acentuados, mostrando que esta espécie é extremamente sensível ao herbicida, indicando os perigos do uso indiscriminado deste agroquímico.

Os estudos desenvolvidos com o rabanete em comparação com a couve, mostraram que os efeitos do glifosato na toxicidade crônica e aguda foram muito mais intensos no rabanete.

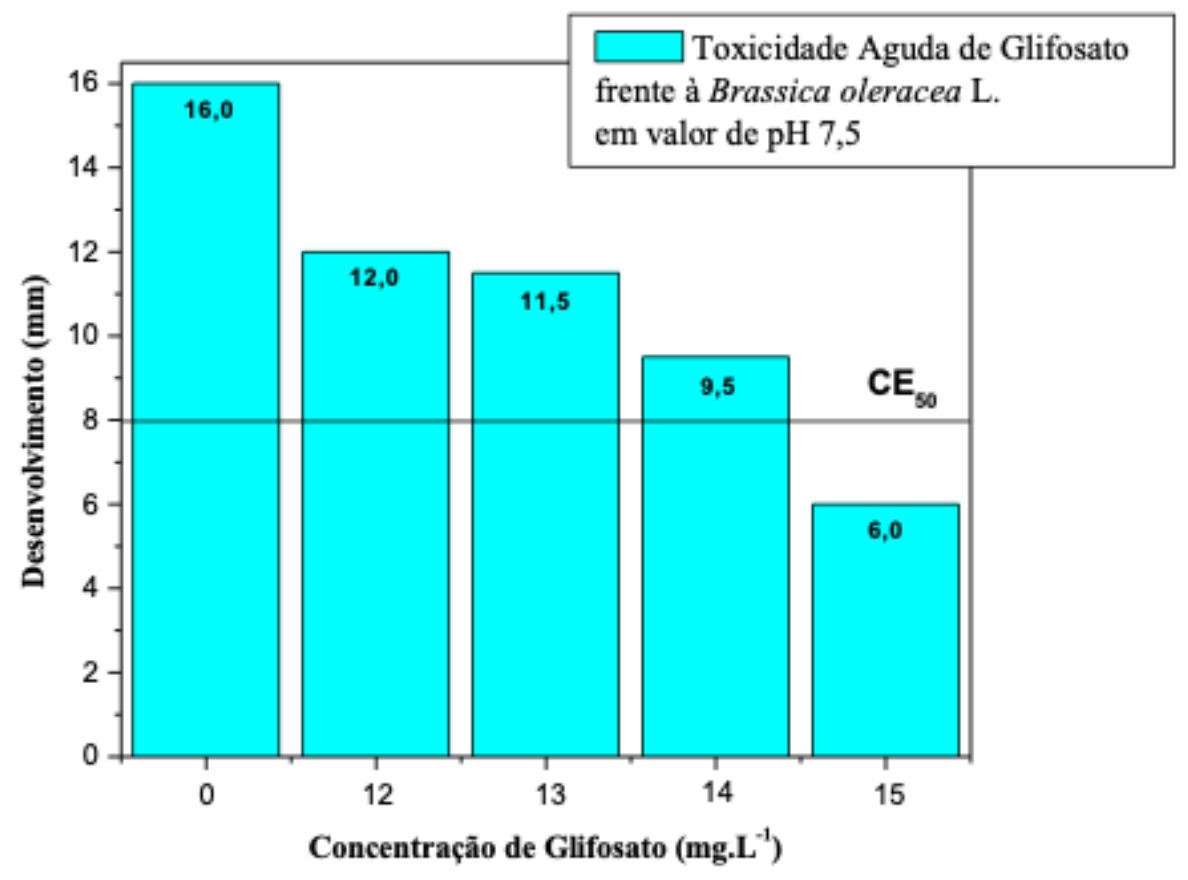

Figura 1 - Estudo da toxicidade aguda dos efeitos de concentrações do glifosato para a couve (Brassica oleracea L.) 


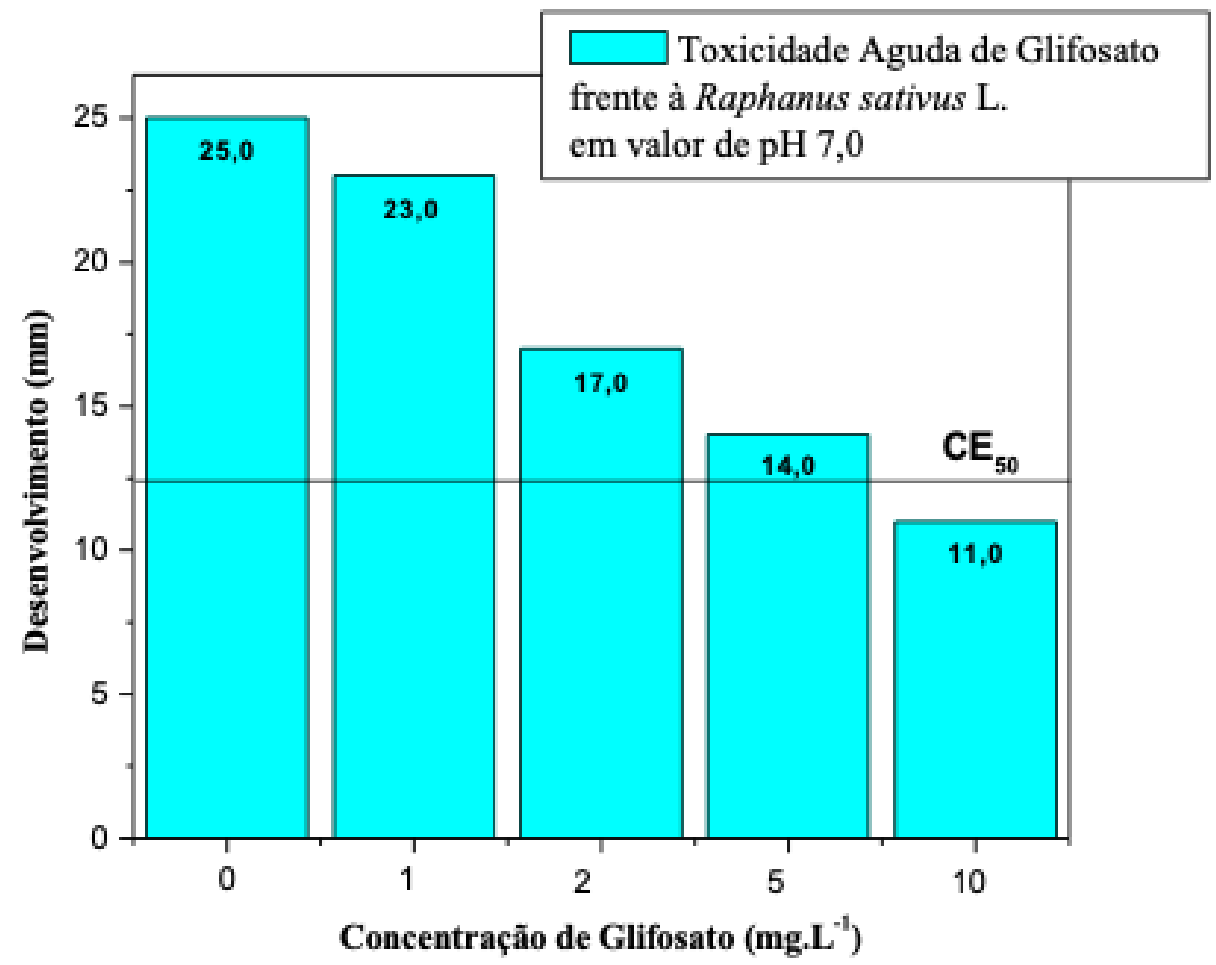

Figura 2 - Estudo da toxicidade aguda dos efeitos de concentrações do glifosato para o rabanete (Raphanus sativus L.)

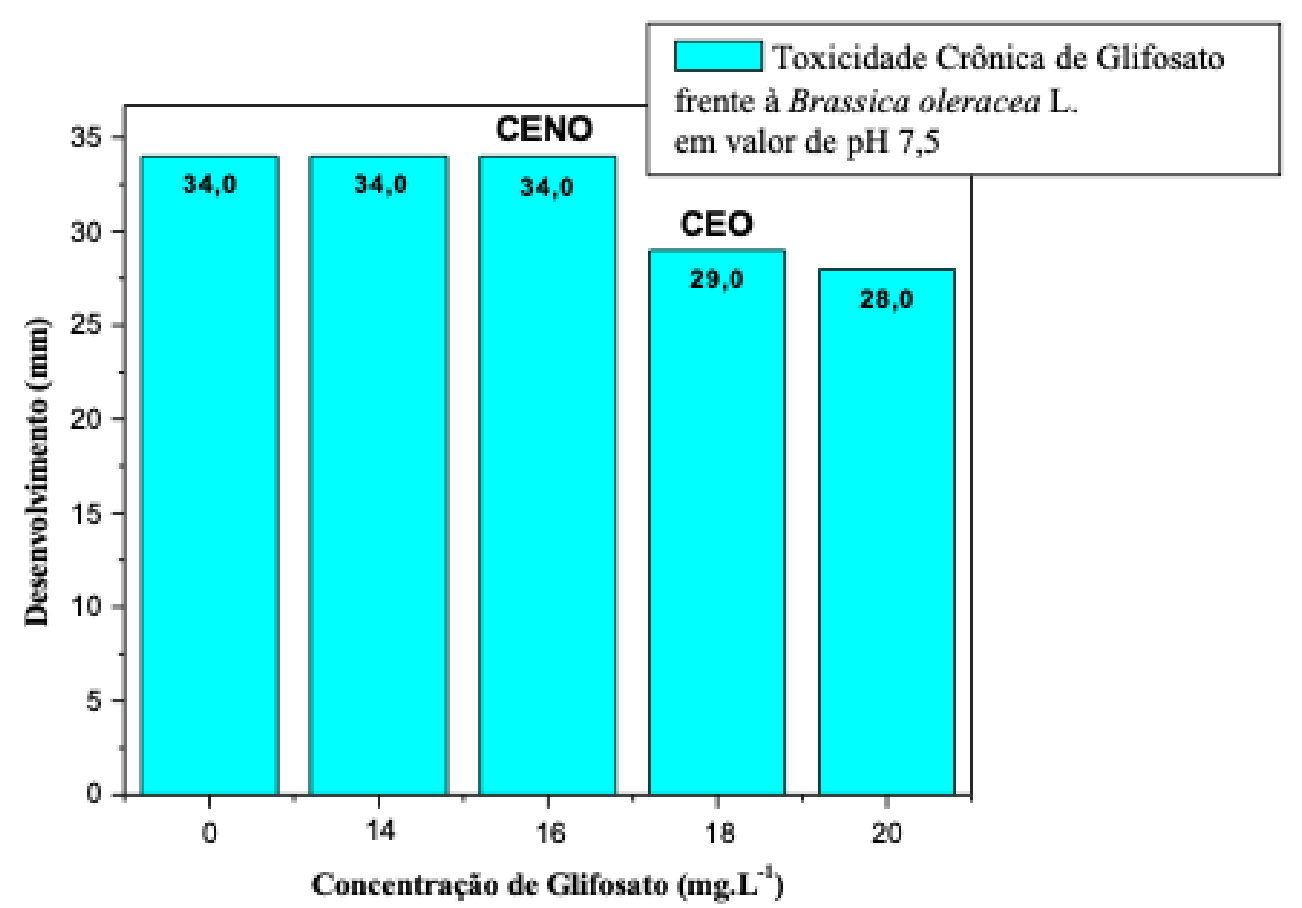

Figura 3 - Estudo da toxicidade crônica dos efeitos de concentrações do glifosato para a couve (Brassica oleracea L.) 


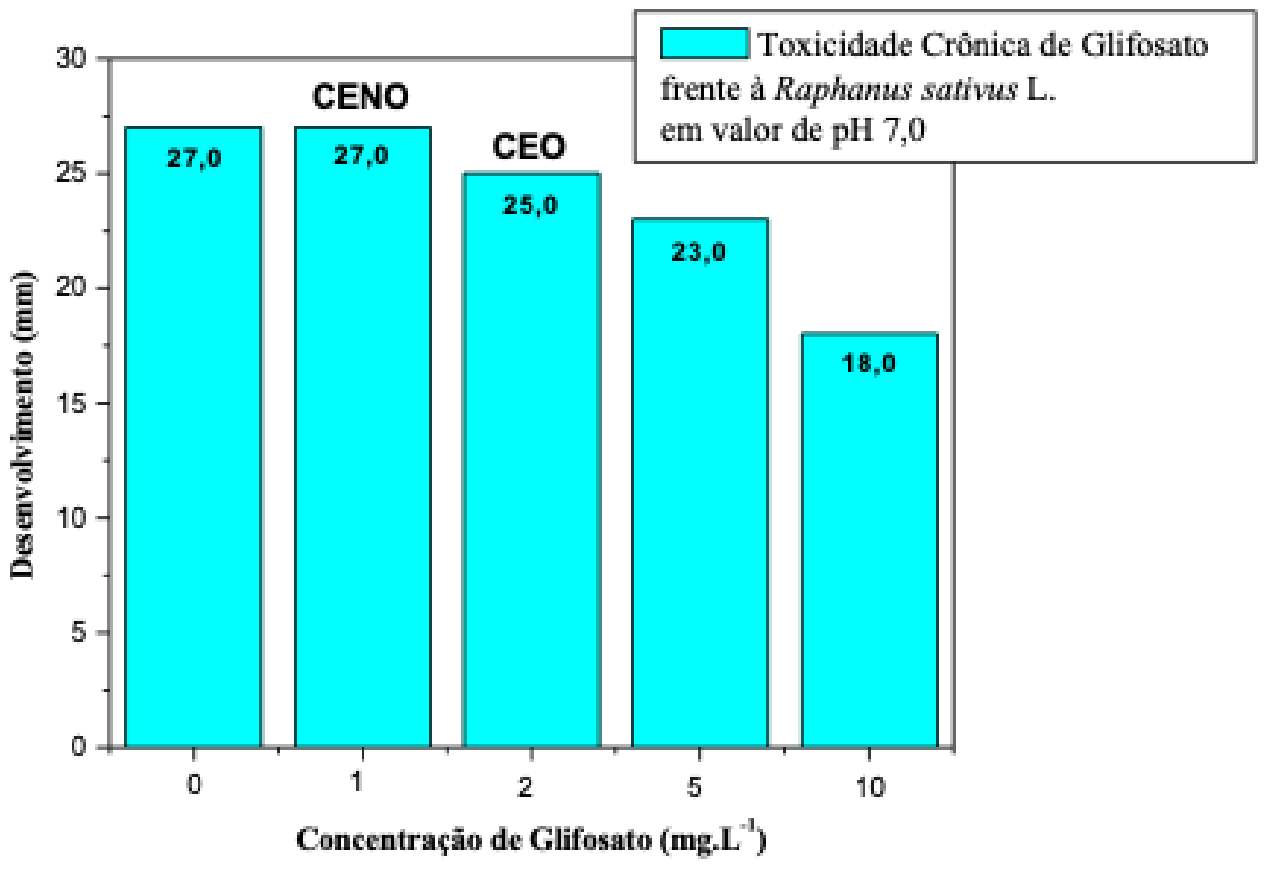

Figura 4 - Estudo da toxicidade crônica dos efeitos de concentrações do glifosato para o rabanete (Raphanus sativus L.)

\section{CONCLUSÕES}

Por meio deste estudo pode-se verificar a elevada toxicidade do glifosato frente às espécies Raphanus sativus. L e Brassica oleracea L., indicando que o glifosato pode ser extremamente agressivo quando usado indiscriminadamente.

O uso excessivo na agricultura pode levar a resistência das plantas ao produto, $\mathrm{o}$ que demandaria novos agroquímicos, além dos riscos ambientais, principalmente os danos causados a corpos d'águas dados a elevada solubilidade dos herbicidas. Compostos orgânicos sintéticos são xenobióticos e podem apresentar riscos ao ciclo biogeoquímico no meio aquático, de modo geral, eles adsorvem em material particulado orgânico e são assimilados

\section{AGRADECIMENTOS}

Este estudo foi desenvolvido a partir do Programa de Educação Tutorial - PET Licenciatura em Química (PET/MEC/SESu/DIFES), Centro de Ciências Agrárias (CCA) - Universidade pelos organismos detritívoros e/ou pelo fitoplâncton, através do qual chegam aos peixes e ao homem (BOTTA-PASCHOAL \& ROCHA, 2002).

Durante o ciclo de assimilação, excreção e reassimilação na cadeia alimentar, esses agentes químicos se concentram e se acumulam ao longo da mesma, em níveis bastante superiores em relação à concentração na água (BOTTAPASCHOAL \& ROCHA, 2002). Devido ao grande risco que representam para os ecossistemas as avaliações ecotoxicológicas dos agroquímicos têm sido reconhecidas como extremamente necessárias.

Federal de São Carlos (UFSCar). Os autores agradecem o suporte técnico e as bolsas cedidas pela CAPES por meio do Programa PET. 


\section{REFERÊNCIAS BIBLIOGRÁFICAS}

AMARANTE JR., O.P. de. Avaliação do potencial de contaminação por herbicidas: determinação do 2,4-D e do seu principal produto de degradação em solos de campos de cultivo de eucaliptos. Dissertação (Mestrado em Química), Universidade Federal do Maranhão, p. 12, São Luís, 2002.

BOTTA-PASCHOAL C. M. R.; ROCHA, O. Avaliação ecotoxicológica de sedimentos em reservatórios da Bacia do Rio Tietê, SP, com ênfase na aplicação do estudo de Avaliação e Identificação da Toxicidade. Tese de Doutorado. Escola de Engenharia de São Carlos. USP. 2002.

DA CRUZ, L. H.; DE SANTANA, H.; ZAIA, C. T. B. V.; ZAIA, D. A. M.; J. BRAZ. Chem. Soc., submetido; - - Da Cruz, L. H.; Dissertação de Mestrado, Universidade Estadual de Londrina, Brasil, 2002.

GRISOLIA, C. K. Agrotóxicos: mutações, câncer \& reprodução. Editora Universidade de Brasília, 392 p. 2005.

GRUYS, K. J.; SIKORSKI, J. A. Inhibitors of Tryptophan, Phenylalanine and Tyrosine Biosynthesis as Herbicides. Dekker, New York, 1999.

PELEGRINI, R. T.; MEDINA, A. F.; MENDES, F; MOLENA, J. C.; GREVE, L. F.; SALMAZO, L. G. S.; MILANI, P.
A.; ANDRADE, P. G.; TOGNOLI, R. B. Metodología de evaluacifón ecotoxicológica empleando germinación de semillas en gel nutriente como medio de cultura. Revista Ambiente Água. v.9 n.2, p. 359-372, 2014.

SILVA, M. D. Biomonitoramento de uma reserva particular do patrimônio natural - RPPN - através do estudo de biomarcadores em Astyanax sp. Monografia apresentada ao Curso de Ciências Biológicas, Universidade Federal do Paraná, 2004.

SOUZA, D. S. S.; RAMOS, J. L.; DIAS, A. B.; PORTELA, A. L. R.; VILLA, F. B.; GODOY, G. B.; CRISTIANO, G. A.; GODOI, I. R. G.; MONTEIRO, J. O. F.; GABRIEL, L.; VOLPE, M. C.; NEVES, V. D. D.; SEBASTIANI, R.; PELEGRINI, R. T. Estudo da Toxicidade da Ureia na Germinação de Rabanete e Couve. Brazilian Journal of Biosystems Engineering. v.13, n. 3, p. 263-271, 2019.

TONI, L. R. M.; SANTANA, H.; ZAIA, D. A. M. Adsorção de glifosato sobre solos e minerais. Química Nova, Londrina, v. 29, n. 4, p, 829-833, 2006.

YAMADA T.; CAMARGO P.R. Efeitos do glifosato nas plantas: Implicações fisiológicas e agronômicas. Informações agronômicas, n. 119, setembro de 2007. 